\title{
Redescriptions of two anomuran crustaceans, Uroptychus japonicus Ortmann, 1892 (Chirostylidae) and Munidopsis taurulus Ortmann, 1892 (Galatheidae), based upon the type material
}

Keiji Baba

Abstract.-Uroptychus japonicus Ortmann, 1892 and Munidopsis taurulus Ortmann, 1892, both known only from Japan, are redescribed based upon the type material, now in the collection of the Musée Zoologique, Strasbourg. Munidopsis hastifer Benedict, 1902, another species known only by the type material from Japan, is synonymized with M. taurulus.

\section{Introduction}

In his list of anomuran crustaceans from Japan, Miyake (1982) listed 23 species (including one subspecies) of Uroptychus and 11 species (including one subspecies) of Munidopsis, which included two problematic species, Uroptychus japonicus Ortmann, 1892 and Munidopsis taurulus Ortmann, 1892, which were based on brief original species' accounts. The types are now in the Musée Zoologique, Strasbourg (MZS). In this paper, morphological descriptions of the two species are updated. In addition, Munidopsis hastifer Benedict, 1902, known only from the Japanese type material is synonymized with $M$. taurulus, on examination of the types of the former, now in the collection of the National Museum of Natural History, Smithsonian Institution (USNM).

The measurements given in parentheses in the text indicate the postorbital carapace length, the distance between the orbital margin and the posterior margin of the carapace in midline.
Family Chirostylidae

Uroptychus japonicus Ortmann, 1892

Fig. 1

Uroptychus japonicus Ortmann, 1892: 248, pl. 11: figs. $3,3 \mathrm{~b}, \mathrm{c}, \mathrm{f}, \mathrm{g}, \mathrm{h}, \mathrm{i}, \mathrm{z}$.

[Not Uroptychus granulatus var. japonicus Balss, 1913: 25, fig. 18 (Sagami Bay) = Uroptychus occultispinatus Baba, 1988]

Material examined.-Sagami Bay, 200 fms $(366 \mathrm{~m}): 2$ o $(3.3,3.5 \mathrm{~mm}), 1$ ov $q$ ( 4.0 $\mathrm{mm}), 1$ ㅇ $(3.8 \mathrm{~mm})$, syntypes, MZS 348 .

Designation of types.-The ovigerous female is selected as the lectotype, and the others are paralectotypes.

Eggs.-Number of eggs carried, 3; size, $1.55 \times 1.24 \mathrm{~mm}$.

Description.-Carapace slightly broader than long (1.07 times as broad as long), relatively wide anteriorly; dorsal surface convex from side to side and anterior to posterior, anteriorly leading to rostral tip without distinct break by depression; no border between gastric and cardiac regions; covered with faint granules often provided with very fine short setae; lateral margins convex, bearing posteriorly diminishing spines, first anterolateral, well developed, directed mesially, somewhat distantly lateral to small lateral orbital spine, second smaller than, and, remote from first, placed on anterior end of branchial region, and distinctly dorsal to level of first, third to seventh nearly equidistant from one another, third more remote from second than from fourth, seventh followed by ridge leading 

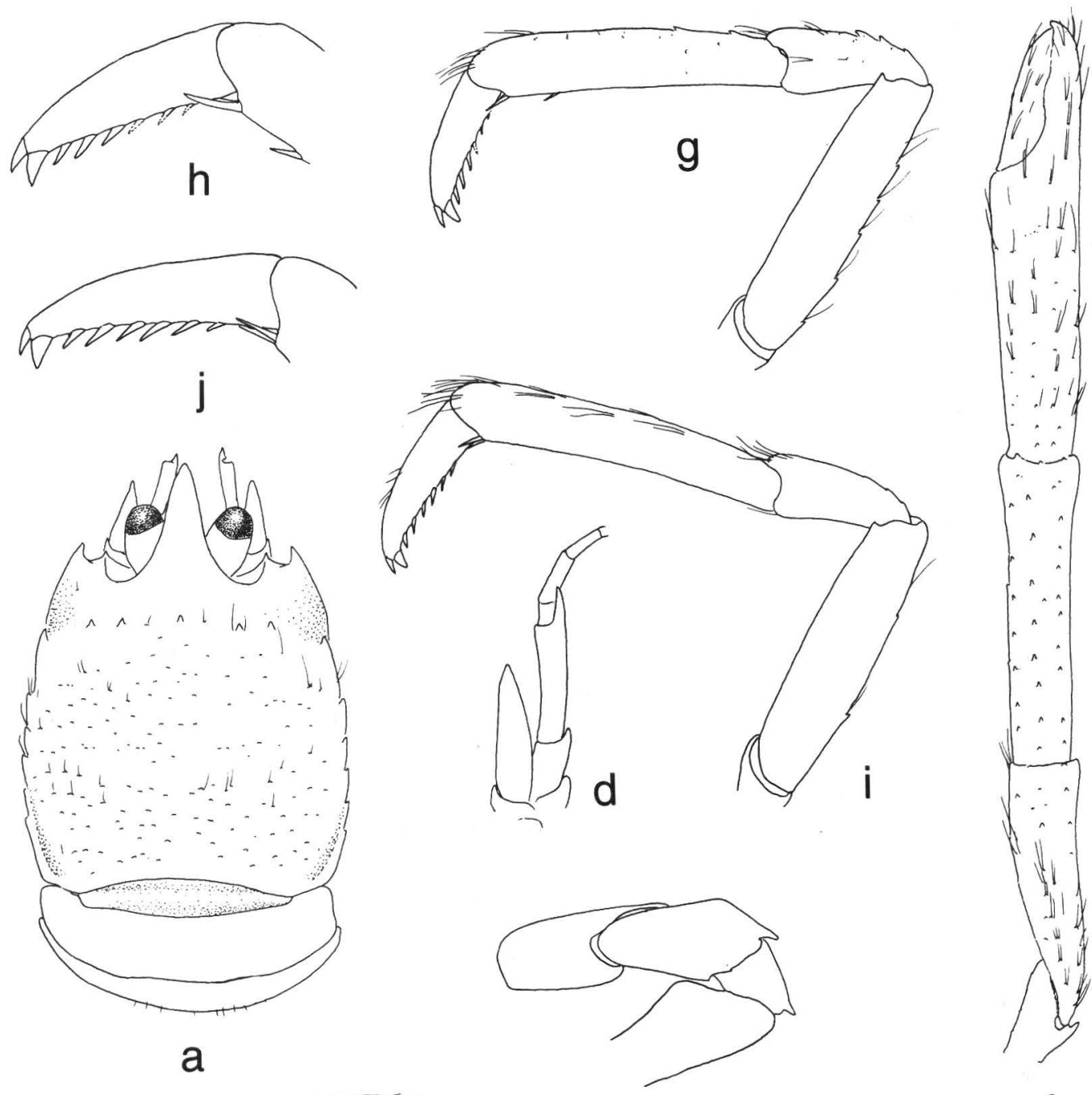

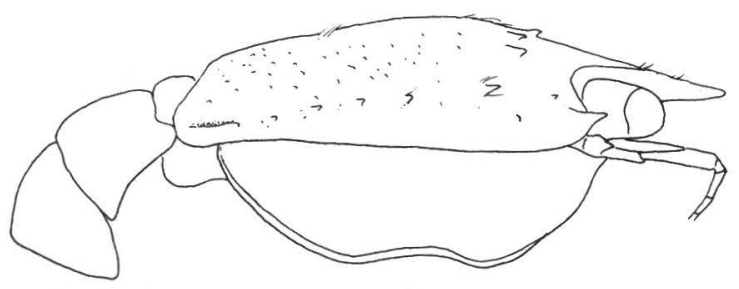

b

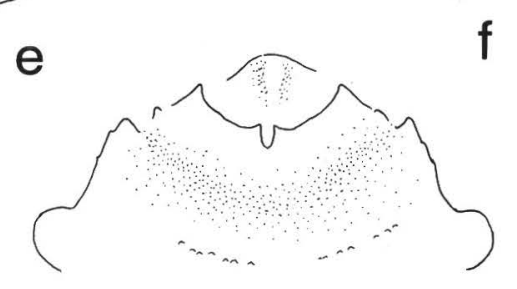

C

$$
1
$$
2 3 4 5 6

Fig. 1. Uroptychus japonicus Ortmann, 1892, ovigerous female lectotype $4.0 \mathrm{~mm}$, MZS 348: a, carapace and anterior part of abdomen, dorsal; b, same, lateral, granules on anterior part of pterygostomian flap omitted; c, anterior part of thoracic sternites, ventral; d, right antenna, ventral; e, endopod of right third maxilliped, distal part omitted, lateral; f, right cheliped, dorsal; $g$, left first walking leg, lateral; h, distal part of same, lateral; i, left second walking leg, lateral; $j$, distal part of same, lateral. Scales $=1 \mathrm{~mm}$; scale 1 for c; scale 2 for f; scale 3 for a, b; scale 4 for $\mathrm{g}$, $\mathrm{i}$; scale 5 for $\mathrm{d}$, e; scale 6 for $\mathrm{h}, \mathrm{j}$. 
to posterior end; anterior gastric region with transverse row of 5 spines, median spine absent in all paralectotypes. Rostrum subtriangular; dorsal surface flattish, ventral surface straight horizontal; length less than half that of remaining carapace. Pterygostomian flap finely granulose on anterior surface, anteriorly ending in sharp spine.

Depressed part of anterior sternites corresponding to first to third maxillipeds anteriorly convex, surface with weak ridge in midline; third thoracic sternite of sternal plastron moderately depressed, anterior margin well excavated, laterally angular, centered by distinct U-shaped notch flanked by very small spine; fourth thoracic sternite with row of tubercles arranged transversely, anterolateral margin anteriorly ending in small process followed behind by a few obsolescent spines, length less than 1/4 width, and distinctly less than half width of third thoracic sternite.

Abdomen sparingly covered with short fine setae; first segment with rounded transverse ridge; second segment rounded on anterolateral corners of pleura.

Eyestalks relatively short, distally narrowed, lateral margin distinctly convex.

Antennal peduncles reaching end of rostrum; ultimate article more than twice as long as penultimate when measured in ventral midline, each article with strong distomesial spine; antennal scale nearly as wide as opposite peduncle, overreaching mid-length of but falling far short of end of ultimate article.

First maxillipeds separated at base. Third maxillipeds barely setose except for brushes; ischium thick, with very small obsolescent denticles on crista dentata, flexor margin without rounded distal corner; merus compressed along flexor margin bearing a few obsolescent denticles distal to mid-length; distolateral spine distinct on merus and carpus.
Chelipeds slender, subcylindrical, sparingly setose, covered with small spines or tubercular processes roughly arranged in longitudinal rows but obsolescent on distal portion of palm, barely discernible on fingers; length 4.5 times that of carapace excluding rostrum; distodorsal spine of basis-ischium and ventro-distomesial spine of merus distinctly larger; carpus slightly longer than palm; movable finger slightly more than half length of palm.

Walking legs sparingly setose, moderately compressed; meri distinctly shorter than postorbital carapace length on first walking leg, dorsal margin with ca. 5 small spines on first leg, obsolescent on second and third legs, ventral margin with small terminal spine; carpi short, less than half as long as propodi, extensor margin with a few spines distinct on first walking leg, obsolescent on second and third; propodi entire on flexor margin except for pair of spines located at end, length less than twice that of dactylus on first leg, slightly greater on following legs; dactyli with slightly curving flexor margin bearing somewhat inclined, slender, proximally diminishing spines but stout penultimate, ultimate and penultimate nearly contiguous at base, third and remaining spines loosely arranged.

Remarks.-The cervical groove clearly depicted by Ortmann (1892: pl. 11, fig. 3) is, in fact, barely discernible.

There is no close relative of this species in Japanese waters. The carapace having convex lateral margins and an inflated dorsal surface, propodi of walking legs having pair of distal spines on the flexor margin displayed by the species, suggest a resemblance to $U$. convexus Baba, 1988 from the Philippines. However, the latter species has more elongate eyestalks, fewer and stouter spines on the walking leg dactyli and the ultimate antennal article lacking a distomesial spine, to mention the most obvious differences. 
Family Galatheidae

Munidopsis taurulus Ortmann, 1892

Fig. 2

Munidopsis taurulus Ortmann, 1892: 256, pl. 11: figs. 13, 13a, i.

Munidopsis hastifer Benedict, 1902: 284, fig. 28.

Material examined.-Sagami Bay, 200 fms $(366 \mathrm{~m}): 1$ ov. $+(5.3 \mathrm{~mm})$, holotype, MZS 354.

Description.-Carapace moderately arched from anterior to posterior and from side to side, areolations distinct, protuberant, armed with compressed spines of irregular sizes and small tubercle-like spines; well excavated cervical groove between gastric and cardiac regions, gastric region well inflated, procurved spines of moderate size roughly flanking midline, length 1.17 times greatest width; lateral margins subparallel, anterolateral spine small, remotely lateral and posterior to level of lateral orbital angle, followed behind by depressed, procurved spines of irregular sizes; posterior margin preceded by elevated ridge bearing row of procurved spines. Rostrum $1 / 3$ as long as remaining carapace, dorsal surface with longitudinal ridge in midline, proximally bearing very small spines; lateral margins somewhat concave on posterior half between eyes, serrate on anterior half, convergent to acute apex; ventral surface horizontal, smooth. Lateral orbital angle produced, leading obliquely to point half way to anterolateral spine of carapace, then transversely to it. Pterygostomian flap covered with tubercle-like small spines, anteriorly ending in sharp, narrow, triangular process.

Third thoracic sternite narrow, with opposed lobes on anterior margin, width about $1 / 3$ that of fourth thoracic sternite; fourth thoracic sternite short subtriangular, shallowly depressed on anterior surface.

Second and third abdominal segments with compressed, procurved spines arranged in anterior and posterior rows as illustrated; fourth with anterior and posterior ridges without spines, each pleuron with 1 or 2 small spines. Telson composed of 7 plates, length-width ratio 0.89 , pair of posterior plates wider than long.

Eyes slightly movable, wide and short, cornea wider than long; very small eyespine arising from anteriorly produced dorsal end of eyestalk (cornea excluded).

Basal article of antennule inflated distolaterally, bearing irregular small spines at periphery; strong distolateral and distodorsal spines, former with small accompanying spine ventral to it; distal margin bearing small spines. Antennal peduncle with basal article somewhat produced at anterior end of ventral side, distolateral corner anteriorly produced; second article with 1 small distomesial and 1 stout distolateral spine; third article distinctly narrower than second, bearing 1 distomesial and 2 distolateral spines.

Ischium of third maxilliped slightly shorter than merus when measured along lateral midline, lateral surface flattish, flexor margin anteriorly ending in spine accompanied by a few spines proximal and lateral to it, extensor margin with strong distal spine; crista dentata with 16 denticles diminishing toward proximal end; merus distally narrowed, bearing 5 distally diminishing spines on flexor margin and 5 smaller spines on extensor margin, lateral surface also with small or tubercle-like spines; carpus with row of spines along extensor margin.

Epipods absent from all pereopods.

Chelipeds about 3 times as long as carapace excluding rostrum, relatively slender, surface with small spines of irregular sizes arranged roughly in longitudinal rows, except for fingers covered with very small spines; merus longer than palm but shorter than chela (palm and fingers combined), mesial margin with 3 pronounced spines remote from one an- 

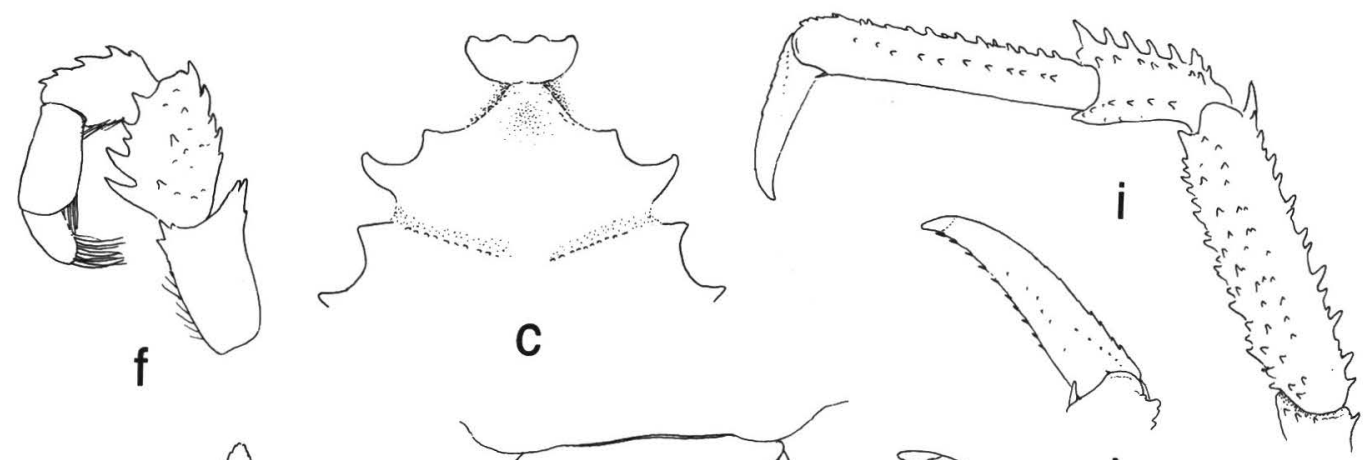

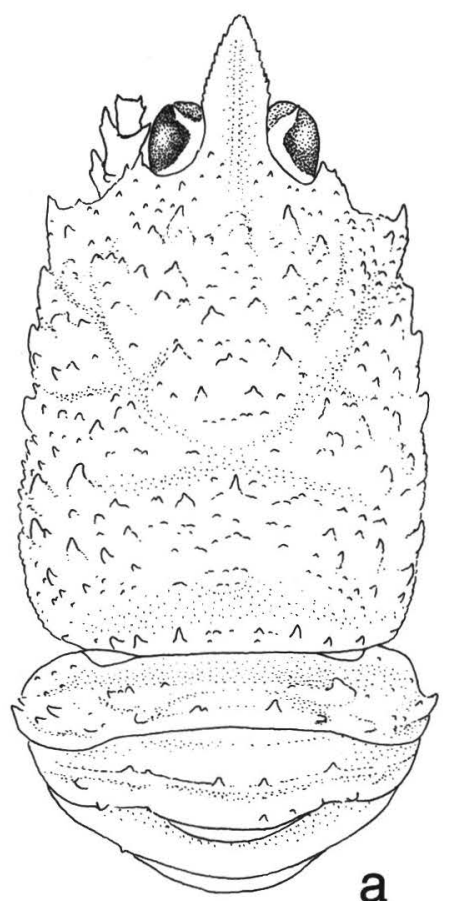

a

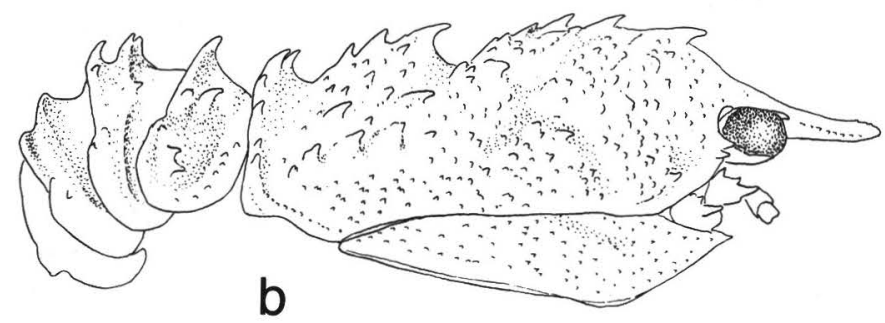

1 2 3
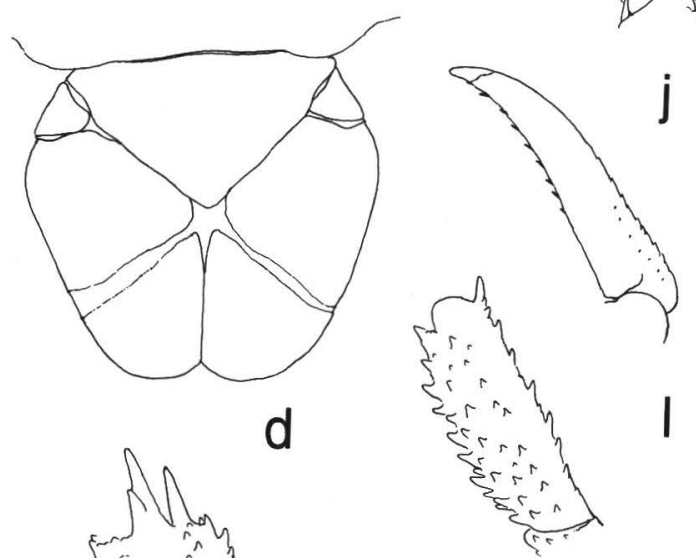

$\mathrm{k}$

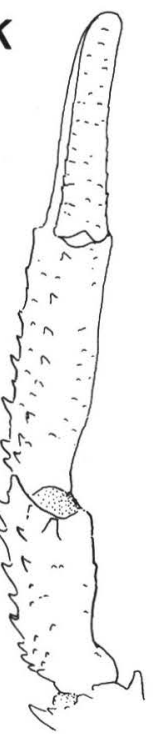

$\mathrm{h}$

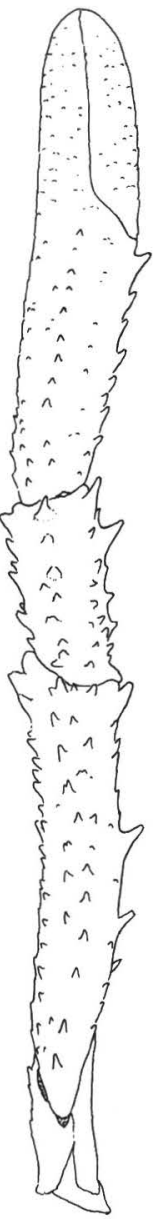

g

Fig. 2. Munidopsis taurulus Ortmann, 1892, holotype ovigerous female, $5.3 \mathrm{~mm}$, MZS 354: a, carapace and anterior part of abdomen, dorsal; b, same, lateral; c, anterior part of thoracic sternites, ventral; d, telson; e, left antennule and antenna, ventral; f, endopod of left third maxilliped, lateral; g, left cheliped, lateral; h, distal half of same, mesial; i, left first walking leg, lateral; $j$, distal part of left second walking leg, lateral; $k$, merus of left third walking leg, lateral; 1 , dactylus of left third walking leg, lateral. Scales = $1 \mathrm{~mm}$; scale 1 for a, b; scale 2 for $\mathrm{g}$, h; scale 3 for i, k; scale 4 for c, d; scale 5 for e, f, j, l. 


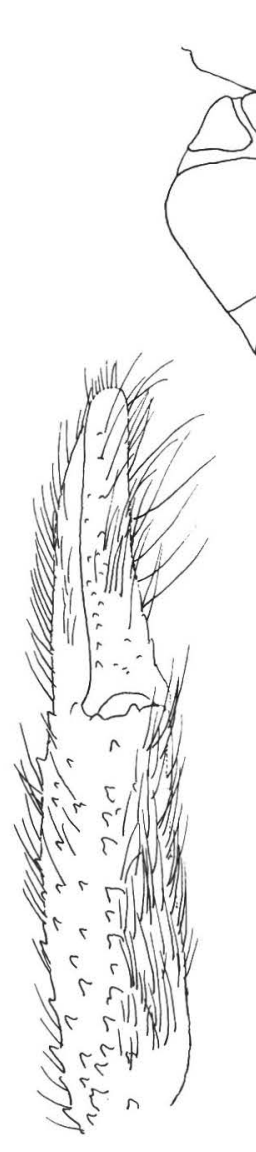

d



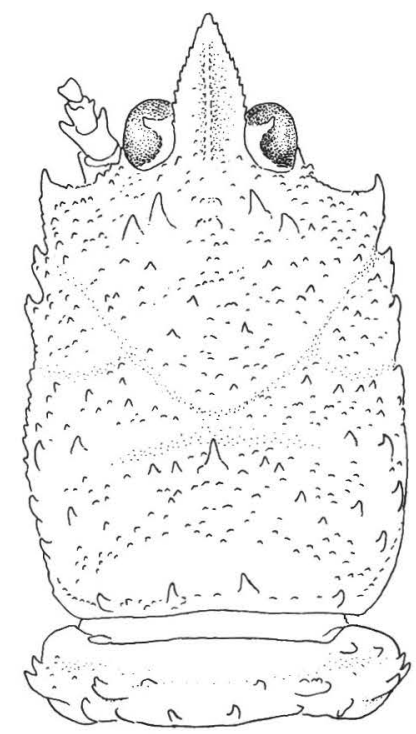

b

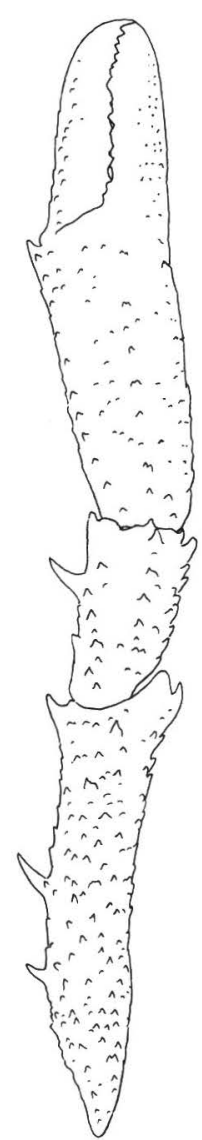

e

\section{$1-2-3$}

Fig. 3. Munidopsis hastifer Benedict, 1902, syntypes, USNM 26164; a, d, male 5.8 mm; b, c, e, f, male $6.8 \mathrm{~mm}$ : a, carapace and anterior part of abdomen, dorsal; b, same; c, telson; d, left cheliped, mesial; e, right cheliped, dorsal; $f$, dactylus of left first walking leg, lateral. Scales $=1 \mathrm{~mm}$; scale 1 for a, b, d, e; scale 2 for c; scale 3 for $\mathrm{f}$.

other, median one somewhat closer to proximal one; carpus more than twice as long as broad, 2 pronounced dorsomesial spines near distal end; palm somewhat widened distally, longer than but less than 1.5 times as long as movable finger; fingers not gaping, distally with intermeshing teeth.

Right first, second and third walking legs missing. Left walking legs relatively narrow. Meri successively shorter posteriorly, bearing small spines on lateral sur- face and somewhat cristate dorsal margin, ventral surface with mesial and lateral marginal spines, mesial smaller; carpi having extensor margin with row of acute spines paralleled by 2 rows of smaller spines on lateral surface; propodi slightly less than twice as long as dactyli, bearing 2 rows of spines, one on extensor margin, another on lateral surface; flexor margin ending in pair of movable spines located distally; dactyli slightly curving distally, extensor margin with very small 
spines along proximal half, flexor margin with 8-10 corneous setae.

Remarks.-The morphology of $M$. taurulus described above shows that the species is very close to or may be identical with $M$. hastifer Benedict, 1902. Inasmuch as the original description and illustration of $M$. hastifer lacked detail of the eyes and dactylar spination of walking legs and the presence or absence of epipods on the pereopods, the type material of Munidopsis hastifer Benedict, 1902 was examined. It includes three males $(5.8,6.8,8.9 \mathrm{~mm})$ (USNM 26164), collected off Honshu Island, Japan, 60 miles E of Manazuru Zaki, Kanagawa, Sagami Bay, 120-265 fm (219-485 m), gray mud and volcanic sand, 5 May 1900 (Fig. 3).

Undoubtedly, $M$. hastifer can be synonymized with $M$. taurulus. Although the following minor differences are found, they are merely individual or sexual variations: In the types of $M$. hastifer, the compressed, procurved spines are more pronounced on the carapace; chelipeds and walking legs are covered with more numerous small spines, and setose as illustrated (Fig. 3d); dactylar spines and corneous setae on the walking leg dactyli are more numerous; the telson is much wider ( 0.71 times as long as wide), the mid-lateral plates have coarse stiff setae on the lateral margin, a feature apparently indicating a male character, as is known in M. cylindrophthalma (Alcock, 1894) (see Baba, 1988:153).

\section{Acknowledgments}

I thank Elisabeth Lang, Director of the Musée Zoologique, Strasbourg, for access to laboratory facilities, Rafael Lemaitre of the Smithsonian Institution for information on the station data of the Albatross, and the late Raymond B. Manning for loaning the type material of Munidopsis hastifer. A trip to the Musée Zoologique was made possible by Grant-in-Aid for International Scientific Research (No. 12575008) from the Japanese Ministry of Education, Science and Culture (chief scientist: Shunsuke F. Mawatari of Hokkaido University). The manuscript was reviewed by Colin L. McLay of the University of Canterbury.

\section{Literature Cited}

Baba, K., 1988. Chirostylid and galatheid crustaceans (Decapoda: Anomura) of the "Albatross" Philippine Expedition, 19071910. Researches on Crustacea, Special Number 2: $\mathrm{v}+203 \mathrm{pp}$.

Balss, H., 1913. Ostasiatische Decapoden I. Die Galatheiden und Paguriden. In: Doflein, F., Beiträge zur Naturgeschichte Ostasiens. Abhandlungen der mathematisch-naturwissenchaftlichen Klasse der königlich bayerischen Akademie der Wissenshaften, München, 2 (supplement) (9): 1-85, pls. 1, 2.

Benedict, J. E., 1902. Descriptions of a new genus and forty-six new species of crustaceans of the family Galatheidae, with a list of the known marine species. Proceedings of the United States National Museum, 26: $243-334$.

Miyake, S., 1982. Japanese Crustacean Decapods and Stomatopods in Color. Vol. 1. Macrura, Anomura and Stomatopoda. vii + 261 pp., 56 pls. Hoikusha, Osaka.

Ortmann, A., 1892. Die Decapoden-Krebse des Strassburger Museums IV. Die Abtheilungen Galatheidea und Paguridea. Zoologischen Jahrbüchern, Abtheilung für Systematik, Geographie und Biologie der Tiere, 6: 241-326, pls. 11, 12.

Address: Kumamoto University, Faculty of Education, 2-40-1 Kurokami, Kumamoto 8608555, Japan

E-mail: keiji@gpo.kumamoto-u.ac.jp 